\title{
COLABORACIÓN PROFESIONAL
}

\section{LA CONTRATACION MUNICIPAL Y LAS CONCESIONES ADMINISTRATIVAS}

La concesión administzativa es el acto por el cual la Administración concede u otorga a un particuiar la facultad para el cumplimiento de un servicio público o un fin social.

Se tha discutido mucho por los autores cuál es la verdadera naturaleza del acto administrativo por el cual se otorga una concesión.

Para algunos autores, como Zanobini, adquiere una amplitud tan grande el concepto de esta palabra, que la considera como fué la gracia al Derecho Canónico recogiendn, por tanto, en ella todos aquellos actos en virtud de los cuales otorga la Administración un privilegio a un particular.

Ha sido una teoría muy extendida la de considerar la concesión administrativa como un simple contrato análogo al Derecho Civil. Efectivamente como un contrato se puede considerar la concesión administraliva en algunos aspectos de la misma, y, si bien, algunos requisitos de los que la Legislación Civil establece como fundamentales son asimismo de aplicación a la concesión administrativa, tiene igualmente otros que le diferencian esencialmente del contrato civil; en el contrato civil es una de las características esenciales el acuerdo de las voluntades de las partes contratantes sobre la obra, servicio u objeto del contrato; a este acuerdo se llega en un plano de igualdad en el que cada una de las partes defiende su derecho; en la concesión administrativa no se encuentran en un plano de igualdad las partes contratantes, sino que la Administración, desde un plano superior, establece las condiciones po: las que se ha de regir la concesión administrativa, las que podrán ser aceptadas o rechazadas por el particular, pero en ningún caso discutidas, toda vez que éstas son concedidas en virtud de "merced" o "gracia" que otorga la Administración; así vemos que el profesor Fernåndez de Velasco da de ella la siguiente definición: Gracia, merced o reconocimiento, expreso o tácito, que se otorga por la Administración mediante ciertos requisitos o formalidades confirmando un derecho, permitiendo el ejercicio del mismo o creándolo, bien a solicitud de un particular, bien por oferta administrativa.

Entre los autores que le consideran como un contrato, tenemos al Sr. Alvarez Gendín, quien dice que asi como en el derecho privado existen 624 los contratos de compra-venta, prenda, hipoteca, arrendamiento, en el de- 
recho público se diversifica a su vez en diversas ramas que toman el carácter de contratos de Obzas Públicas, Empréstitos, Suministros, Concesiones, etc. El Profesor Sr. Gascón y Marín considera la concesión administrativa como un acto administrativo totalmente separado del contrato y asi dice: I as concesiones se otorgan, los contratos se estipulan, y la defino como "el aclo de la Administración en vistud del cual se otorga medianto determinadas condiciones a un servicio de interés general prestado por un farticular, carácter de servicio público, como si fuera realizado por la propia Administración". Por último, tenemos autores como el Sr. Royo Vilianova, que consideran la concesión mirada desde un aspecto total, como la combinación de dos elementos: el acto administrativo por el cual se instituye legal y reglamentariamente el servicio, regulando. su organización y funcionamiento, y el contrato o acuerdo de voluntades por el que la Admiuıstración y el concesionario regulan su situación jurídica individual, fijando los beneficios ecunómicos del concesionario, tarifas máximas, etc.

En el Derecho español no se encuentra una reglamentación general para las concesiones administrativas y particularmente en relación con el Derecho municipal, teniendo necesidad para cada caso de concesiones de examinar una amplia Legislación diseminada en múltiples disposiciones y en las que no se establecen las condiciones minimas que deberían exigirse para la validez de cada concesión administrativa, y en las que encontramos, asimismo, que en unas tiene autonomia suficiente el Municipio para otorgar dicha concesión y en otras queda limitada la facultad del Municipio a establecer las condiciones de carácter económico por las que se ha de regir la concesión. Sería, pues, muy de desear que en la próxima Ley Municipal se recogiese dándole unidad toda la materia, hoy dispersa, que regula las condiciones administrativas de carácter municipal, estableciendo asimismo las condiciones minimas, como hace el Derecho Civil, para los contratos, que habrian de reunir para su validez las concesiones administrativas. Ya que, al concederse u otorgarse las concesiones administrativas en determinados casos, como ya indicamos anteriormente, por autoridades superiores, generalmente encargadas de vigilar el aspecto técnico del aprovechamiento de los biones municipales, éstas olvidan requisitos que deberían ser fundamentales para la validez de una concesión administrativa.

En confirmación de lo anterioumente expuesto vamos a examinar brevemente una concesión administrativa otorgada por una $R$. O. del Ministerio de Fomento, en la que se olvidó uno de estos requisitos fundamentales, que deberfa ser causa suficiente para considerar nula la concesión que la misma otorgó, ya que, si consideramos el Derecho Civil como supletorio del Administrativo o seguimos la doctrina de los Profesores que consideran las concesiones administrativas como un contrato, el requisito olvidado en esta concesión serf́a causa de nulidad de contrato.

Efectivamente, por el señor $X$ se solicitó del Distrito Forestal de $M$. la ocupación de unos terrenos de los Propios de las Villas de C. y N., con el fin determinado de construir en los mismos una Ciudad Sanitaria, $y$ por $R$. O. dictada por el Ministerio de Fomento en 16 de abril de 1920 , se. le autorizó la ocupación de los terrenos que solicitaba 625 
y para los fines establecidos en la instancia del peticionario. Estamos, pues, en el caso de una concesión otorgada por la Administración a instancia de un particular, pero ni en esta $R$. O. de concesión ni en la aclaratoria dictada cón fecha 16 de junio de 1921 se fijaba el plazo para la construcción de lọ edificios de carácter sanitario, para cuyos fines solicitaba el peticionario el derecho de ocupación de los terrenos.

Si seguimos la doctrina del profesor Roya Villanova, y consideramos la concesión administrativa como un verdadero contrato, no cabe la menor duda de que la falta de este requisito es causa suficiente para considerar nula esta concesión administraliva toda vez que como requisito indispensable para toda clase de contratos establece el Código Civil en sus artículo 1.124 que el incumplimiento de las obligaciones contratadas por una de las partes contratanles es causa de nulidad del contrato, y en el 1.256, establece que la validez y el cumplimiento de los contratos no puede dejarse al arbitrio de uno de loś contratantes.

Y es curiosa la doctrina sentada por el Ministerio de Fomento a unas reclamaciones formuladas por los Ayuntamientos propietarios do. los terrenos, en las que se solicilaba la nulidad de la concesión por incumplimiento del contrato de concesión, toda vez que no se habian destinado los terrenos a los fines que se establecían en la solicitud an-: tes mencionada, pues éste no había edificado ninguno de los inmuebles de que había de componerse la Ciudad Sanitaria, y, acogiéndose a 10 : que debió ser causa de nulidad de este conlratu, si cómo lal se le considera, en la R. O. por la que fué denegada la petición formulada por dichos Alcaldes, cosa que la misma establece en el primero de sus. considerandos, que dice así: "Las condiciones de las concesiones administralivas olorgadas a particulares constituyen las cláusulas de un verdadero coutrato celebrado entre éstos y la Adininistración, de observancia ineludible, tanto para la una como para la olra parte, por: ser la expresión do su voluntad mutua ligada precisamenle por el pacto de que tales condiciones son la expresión", y en el segundo de lós considerandos dice que "ni en la R. O. de concesión ni en la aclaratoria le fué fijado plazo para llevar a cabo la construcción de los edificios proyectados, y que por ello no se le puede fijar a posteriori, porque eslo modificaría los términos de la concesión". Si en el primero de los considerandos le considera como un contrato, ino debe se: de apiicación al mismo lo dispuesto en el Código Civil en su artículo 1.256 ? Si se hubiera de regir el contrato o concesión administrativa por lo dispuesto en el Código Civil, aunque sólo fuera con carácter supletorio y así se determinase por las Leyes Administrativas, no habría lugar a dudas sobre la nulidad de esta concesión adeninistrativa.

Por ello, volvemos a insistir en la necesidad de que este aspecto de la contratación municipal sea recogido y regulado por la nueva Lty Municipal, para que no pueda darse el caso de una concesión adminiștrativa que, desvirtuado el fin para el que fué otorırada, se dedique a otros muy diferentes. 


\section{INFORMACION NACIONAL Y EXTRANJERA}

\section{E S P A N A :}

\section{El Caudillo y las Corporaciones Locales.}

El Ayuntamienio de Sada (Corruna) Itributó a mediados de agosto un fervoroso homenaje de adhesión a S. E. El Jefe del Estado con motivo de la entrega de la Medalla de Oro de la villa y los nombramienros de Alcalde honorario e hijo adoptivo de Sada.

Al recibir esta of renda de la Corporación municipal S. E. El Jefe del Estado tuvo a bien pronunciar las siguientes palabras que nos honramos en recoger en nuestras páginas por estar dirigidas a los municipios de España.

"En estos pequeños ocios que la dirección política de la nación me permite, es para mí muy agradable el poder ponerme en contacto con los municipios españoles y enterarme de las necesidades de cada pueblo. El Ayuntamiento, por ser la institución más antigua de la nación, es donde deben estar mejor representados los intereses de los distintos sectores de los pueblos y la primera rueda en las tareas administraxivas de la nación.

El Estado nuevo no viene a mandar, viene a recoger las ansias del pueblo para convertirlas en leyes y directrices para la Patria. Por eso la Familia, el Ayuntamiento y el Sindicato han de constituir los cauces por donde ha de recibir el Poder público las inspiraciones populares y por donde toda la nación ha de recibir las consignas y las inspiraciones del Estado. Si no reforzamos esíos tres órdenes: Familia, Municipio! y Sindicato, no cabe duda que la gobernación del Estado carecería de contenido, de ese intercambio de ideas, de esa fuente de iniciativas que asciende hacia el Mando y dan medios para que las decisiones del Estado lleguen a los últimos rincones de la nación, haciendol efeciiva nuestra Revolución nacional.

Quiero también repetiros que nosotros no nos dormimos en los laureles, no estamos jamás sa:isfechos de nuestra obra; tenemos unas ambiciones tan extraordinarias para España y para el pueblo, que cuando acabamos una tarea nos hemos empeñado en otra, por eso os encarezco que reforcéis 
los Sindicatos y el Ayuntamiento, cauce natural de vuestras inquietudes, para que podamos mejor conocerlas.

Es necesaria la unión de tados vosotros, la cooperación dentro del Sindicato para tener una voluntad, para que se conozca esa voluntad para exponer luego al Mando las soluciones y asi, con el esfuerzo de todos, se realizarán las grandes obras.

Esta es la misión de la Falange: hacer que la inspiración del pueblol se encauce y no se pierda, pero una inspiración orgánica a través de los organismos naturales del Sindicato y del Municipio.

Deseo en este día muchas felicidades a la villa de Sada y que me considere su Ayuntamienio como un edil más aqui para trabajar por Sada.y por España.

\section{El plan de urbanización de Madrid.}

En el diaria "Informaciones", de Madrid, se han publicado una serie de estudios dedicados a la urbanización del futuro Madrid por el ilustre Arquitecto don Pedro Muguruza, Director General de Arquitectura. Con un gran dominio de la materia ha dedicado interesantes capítulos a comentar la legislación y técnica necesarias para la realización del plan de urbanización general de la ciudad, los problemas de la capitalidad, de la zonificación, del ensanche, etc.

El conjunto de tales problemas que forman parte del nuevo plan se espera tengan cauce legal para su solución en el proyecto de Ley de ordenación urbana de Madrid, sometido por el Consejo de Ministros a las Cories Españolas. El Sr. Muguruza, inicia sus trabajos dando a conocer la organización de la Junta de Reconstrucción de Madrid, que fué creada por Orden del Ministerio de la Gobernación de 27 de abril de 1939, con la misión de formular el proyecto de urbanización de la capital. Posteriormente la Junta de Reconstrucción se reorganizó procurando reunir en su seno todos los organismos interesados en la reforma de Madrid con el criterio de centrar todos los problemas para su consideración y unificar su estudio reuniendo a tal fin todas las técnicas diferentes y necesarias para su desarrollo. A la Co misión Técnica de la Junta corresponde el trabajo de redacción del proyecto de urbanización y el examen de las peticiones de licencias para edificar. con objeto de impedir la creación de dificultades a la realización del plan general. Esta nueva técnica de la Junta ha de completarse con el cuerpo legal que haga posible su realización y a ello tiende la Ley de Bases para la ordenación urbana de Madrid, que determinará la acción del Munici628 pia Madrileño en la realización del plan, las participaciones de todos los 
Municipios y entidades oficiales, la intervención y subvención del Estado y todo to necesario para su ejecución.

El problema de la capitalidad ha sido estudiado detenidamente por el señor Muguruza en todos los aspectos, ya que Madrid, como ciudad, es una entidad urbana con una esfera de competencia propiamente municipal. pero como capital de la Nación reúne un conjunto de territorio afectado por los servicios de la gobernación del Estado, de donde resulta una interferencia de derechos y deberes que necesita encontrar su solución en la nueva legislación. Madrid, por su capitalidad y posición geográfica, tiene el privilegio de ser el centro de las comunicaciones nacionales, y ello afirma su importancia dentro de la órbita de la Nación.

Dentro del plan de ordenación urbana de Madrid, dedica el señor Muguruza uno de sus estudios al problema de la zonificación, para cuya determinación considera indispensable el perfecto conocimiento de la ciudad, su desarrollo y el estado de estructura urbana. La determinación de zonas es fundamental para el porvenir de una ciudad. Los deoretos del Reich, en Alemania y los informes de Barlow, Scott y Utwatt, emitidos por el Ministerio inglés de Urbanismo conceden esencial importancia al sistema de zonificación, que el señor Muguruza aprecia en cinco grupos que responden a la conveniencia general y a razones de lógica organización:

Primero.-Zonas de carácter especial, representativas de orden politica, administrativo, culturales, sanitarias, militares.

Segundo.-Zonas comerciales que comprenden los lugares de máxima concurrencia, incluso los centros de reunión y espectáculos .

Tercero.-Zonas residenciales que constituyen el núcleo inicial de la ciudad, la razón "primum vivere" de la misma.

Cuarto.-Zonas verdes como base $\mathrm{y}$ medio de aislamiento, enlace, esparcimiento y defensa de la ciudad y sus diferentes núcleos.

Quinto Zonas indusiriales onde se concentre orgánicamente este género de actividades indispensable a la vida de la ciudad misma en términos más o menos destacados.

Al ensanche de Madrid ha dedicado el señor Muguruza otro de los estudios que reseñamos, con los que tan aceriadamente ha hecho llegar al gran público los diversos problemas de la ordenación urbana de Madrid de un interés verdaderamente nacional.

\section{El Congreso Urbanistico Hispanoportugués.}

El Ayuntamiento de Madrid, que ha sido invitado para concurrir al Congreso Urbanistico que se celebrará el próximo mes de ociubre en Madrid, Sevilla y Lisboa, ha acordado participar en tan importante Asamblea en 
la que estará representado por varios de sus miembros y por sus prestigiosos técnicos. A dicho Congreso asistirán representaciones de los más importantes Municipios y Diputaciones de Portugal y España.

\section{El proyecto de enlaces ferroviarios de Barcelona.}

Por el Ministerio de Obras Públicas se ha aprobado el proyecto de Enlaces Ferroviarios de la ciudad de Barcelona, cuyas obras serán inauguradas en fecha próxima, constituyendo una importante mejora urbana para la capital barcelonesa. En la actualidad afluyen a Barcelona numerosas vias férreas por los más diversos lugares y algunas tienen que recorrer calles enteras, como la de Aragón, con evidente perjuicio para el vecindario de las casas adyacentes. El nuevo plan supone la electrificación de las lineas que parten de Mataró, Granollers, Martorell y Villanueva y Geltrú; las demás líneas, incluso las del Norte a Manresa y las que afluyen a la Plaza de Cataluña ya se vienen sirviendo de energía eléctrica. Con este proyecto desaparecerán los numerosos pasos a nivel que constituyen un peligro para la circulación y eran un obstáculo para la expansión urbanistica de la ciudad, cuyo desarrollo es uno de los principales objetos del plan aprobado. Otro aspecto importante es la enorme ventaja que proporcionará el que a todos los trenes de viajeros por líneas de vía ancha se tendrá cómodo acceso desde la Plaza de Cataluña o desde el apeadero del Paseo de Gracia.

Con motivo de una visita del Sr. Ministro de Obras Públicas a Barcelona, el Sr. Peña hizo entrega al Ayuntamiento, de la Orden de aprobación del proyecio y de una copia del mismo, expresando su confianza en que gracias al perfecto acuerdo entre los organismos in eresados podrian ponerse muy pronto en ejecución estas obras de tanta importancia para Barcelona.

El presupuesto de las obras asciente a 171.000 .000 de pesetas, de las cuales serán sufragadas por el Estado I 19.500 .000 de pesetas; y el Ayuntamiento aportará 45.500 .000 de pese'as y la Compañia del Metro Transversal contribuirá con 6.000 .000 de pesetas.

El proyecto, cuyas obras serán anunciadas a subasta en plazo breve, beneficiará extraordinariamente el desarrollo urbano de Barcelona, juntamente con las nuevas vías de comunicación establecidas para el aeródromo de Prat, disponiéndose asi la mejor preparación para la expansión comercial de la urbe catalana. 


\section{El Ayuntamiento de Barcelona adquiere el Palacio de la Virreina.}

El Ayuntamiento de Barcelona, procurando satisfacer los deseos de cuantos se preocupan por la conservación de los admirables monumentos de la ciudad, ha adquiridio el Palacio de la Virreina, admirable obra arquitectónica del siglo XVIII, situada en el centro de la ciudad y en uno de los lugares más concurridos, como son las Ramblas. El Ayuntamiento se propone realizar en el Palacio todas las obras necesarias para dignificarlo y adecuarlo a su nuevo destino, que es convertirlo en Museo de Arte.

El acuerdo del Municipio ha sido objeto de general elogio.

\section{El nuevo Museo Maritimo de Sevilla.}

A fines de junio tuvo lugar en Sevilla la inauguración del nuevo Museo Marítimo instalado en la Torre del Oro, a orillas del Guadalquivir. Un acierto exquisito ha presidido tanto en la elección del lugar como en la instalación del nuevo centro que contiene una gloriosa síntesis de la histọia de la Marina española, con un carácter genuinamente sevillano.

En las salas del Museo Marítimo pueden admirarse una colección de retratos de marinos ilustres, grabados de vistas de Sevilla, un estudio cronológico de su desarrollo urbano, y de la canalización del río, cartas de navegación, mapas, reproducciones de barcos y multitud de curiosidades. En los fosos de la histórica Torre del Oro se proyecta la instalación de un acuario.

La notable labor realizada por el Director del nuevo Museo don Julio Guillén, que ya tiene bien probados sus méritos en la dirección del Museo Naval de Madrid, fué objeto de grandes elogios en el acto de la inauguración que alcanzó gran solemnidad.

\section{Las reformas urbanas de Burgos.}

El Ayuntamiento de Burgos ha recibido oficialmente el proyecto de ensanche, saneamiento y reforma interior de la ciudad, que ha sido confeccionado bajo la dirección del Ingeniero y Arquitecto don José Paz Maroto, asistido por varios técnicos burgaleses. El proyecto, que reviste una gran importancia, comprende, en realidad, siete proyectos distintos, integrados en un plan general de obra: Reforma interior del casco antiguo de la capital castellana; ensanche to:al, con una ordenación capaz para I20.000 habitantes; abastecimiento general de aguas, a base del pantano de Alarcón; saneamiento o alcantarillado general del casco antiguo y 631 
su ensanche; depuración de aguas residuales, con instalaciones de sedimentación muy modernas, con tratamiento de fangos y estanques de peces; proyecto de pavimentación total, a base de firmes de hormigón blindado, hormigón vibrado y adoquinado de mosaico, y, finalmente, un proyecto general de alumbrado.

El proyecto de reforma interior comprende un plan general de alineación que rectifique los defectos del casco actual de la población urbana que contiene una detallada Ordenanza que complete la ordenación urbana con la debida reglamentación para las futuras construcciones. Den-. tro de estas Ordenanzas, que son nueve en conjunto, se destacan aquellas de importancia artística que tienden a la protección del carácter arquitectónico y artístioo de la antigua ciudad, cuyo carácter trata de preservarcon previsoras medidas.

El proyecto de ensanche procura crear una serie de zonas verdes y amplias plazas orientando la extensión de la ciudad en sentido Este y el proyecto se completa con los estudios necesarios para el abastecimiento de aguas, alcantarillado, depuración de aguas residuales y alumbrados.

El cálculo económico financiero para la ejecución de estos proyectos que conventirán a Burgos en una moderna ciudad de población hasta 120.000 habitantes, ha sido cifrado en 10.000.000 de pesetas.

\section{Concurso histórico en la Diputación Provincial de Badajoz.}

Para conmemorar el cuarto centenario del establecimiento de la imprenta en la provincia de Badajoz, el Centro de Estudios Extremeños de la Excma. Diputación Provincial de Badajoz organiza un concurso histórico, en el que podrán tomar parte los escritores hispano-americanos que lo deseen.

El tema único será: "La imprenta en Extremadura en los siglos XV y XVI", y el trabajo debe contener noticias y documentos inéditos, e irá acompañado de facsímiles, fotografías y, en general, cuantos elementos gráficos puedan contribuir a la más clara y digna presentación de la obra.

La extensión no podrá ser superior a un volumen en octavo de 300 páginas. 


\section{E X T R A N J ER O :}

INGLATERRA.-La reforma inglesa.-¿CUAL SERA EL FUTUro Del Gobierno I.oc.al?, por O. Lewis Abbott (I). (Conclusión.)

La reforma de la Administración Local ha sido estudiada por las asociaciones de los distintos tipos de entidades territoriales, contemplando cada una el problema deside su peculiar punto de vista, con el consiguiente peligro de obtener tan sólo visiones parciales. Así se nos of recen cuatro aspectos diversos, correspondientes a los aludidos tipos, a saber: a) el condado; b) los grandes burgo-condados y ciudades comunes; c) las pequeñas poblaciones y distritos urbanos; y d) las zonas rurales. Sin embargo, la reforma local debiera considerarse como un todo, pues sólo así pueden apreriarse los efectos de la redistribución de población e industria recomendada en el plan Barlow.

Desde la pasada guerra se regularon las construcciones urbanasi estableciendo una media de densidad que se juzgó indispensable para que las viviendas no se vieran privadas de sol y aire. Tan sólo Londres sobrepasa La cifra fijada. Pero la fijación de esta densidad media, tiene el inconvenien de que para ello no se tuvo en cuenta, además de las viviendas, el número de industrias, de tiendas, de oficinas, almacenes generales, mercados, edificios públicos, escuelas, bibliotecas, etc., $y$ otros datos importantes.

La distribución de la superficie urbana está muy mal hecha. En su misma zona de la población radican y se entrecruzan las actividades más heterogéneas. Es una consecuencia de la revelación industrial del siglo XIX y del "laisser-faire" económico.

La superficie urbana puede descomponerse aproximadamente en: residencias, 40 por 100 ; otros tipos de construcciones, 25 a 30 por 100; espacios libres, 30 a 35 por 100 . (Es de advertir que en algunas ciudades el espacio libre no llega al ro por 100.)

La superficie total de Inglaterra y Gales se halla distribuída del modo siguiente: agricultura efectiva, 82,I por 100; agricultura en potencia, I.I por 100; bosques, 5,5 por 100; superficie no cultivable (edificaciones, caminos, etc.) II,3 por I00. La superficie edificada va aumentando de día en dia. Entre 1925 y 1937, se construyeron cerca de tres millones de edificaciones, el 54 por 100, casas.

Dado el incremento de la población en las ciudades, no les queda más

(1) Véase el númẹno 14 de nueștra Revista. 
solución que anexionarse términos municipales vecinos o subir pisos a las casas, es decir, crecer en superficie o en altura. Sin embargo, muchos propugnan la descongestión de las ciudades, no sólo para hacerlas menos vulnerables a los ataques aéreos, sino también para mejorar las condiciones higiénicas y de trabajo, aunque es difícil creer que las corporaciones locales se decidan a ejecutar su propio desmembramiento desprendiéndose del exceso de población y evacuándola a otras localidades, como seguramente tampoco se conseguirá limitar el incremento de la industria en estas zonas.

En los distintos proyectos de reforma local se trata de armonizar el incremento de viviendas con el industrial y comercial. Se habla de situar la población obrera en ciudades satélites. En este caso los capitalistas deberían subvenir no sólo a los gastos de alojamiento, sino también de desplazamiento de estas familias. Para esta emigración se aprovecharían, algunas veces, localidades existentes, si bien transformándolas por completo. porque aunque una ciudad de un millón de almas tiene sus servicios en condiciones de soportar un aumen'o de 250.000 habitantes, cosa distinta ocurre con una población de 10.000 almas, que sufre una mutación radical si se se agregan otras 25.000 . Cuando no puedan aprovecharse poblaciones contiguas, habría que construír ciudades satélites completamente nuevas. $Y$ es de advertir que la construcción de una nueva ciudad para roo.000 habitantes, por ejemplo, es muche más costosa que la evacuación de dicho número de habitantes a una ciudad ya existente; aunque esta regla tiene un limite porque puede ocurrir que los servicios básicos no alcancen a cubrir las necesidades de la población agregada.

Un problema importante. relacionado con las ciudades satélites, que hay que tener en cuenta, es el relativo a la disminución del valor rentable de la ciudad originaria, que trae como consecuencia grandes dificultades para sobrellevar las cargas presupuestarias de los antiguos servicios, cargas agravadas por las inversiones hechas en la construcción de la nueva ciudad.

Aunque la construcción de ciudades satélites no pasa de ser un mero proyecto que aún no ha prosperado, es bueno señalar, como se ha hecho, los problemas que plantea y que debieran resolverse antes de seguir adelante.

Por esto cabe preguntar, mientras el proyecto de dispersión de los núcleos urbanos está en proceso evolutivo, si no sería mejor mantener intactas las actuales bases de la administración del condado. Porque, por otra parte, la evacuación de cierto número de habitantes de las grandes aglomeraciones no les haría perder su carácter de zonas superpobladas, y, por 634 tanto, no hay motivo para que no sea estudiado el gobierno local de las 
grandes ciudades y se procure adaptarlo a las condiciones y circunstancias que en ellas se dan.

Ante todo, habria que ver si las entidades locales han cump!idor satisfactoriamente con su cometido. A este respecto recordemos que su actuacion ha merecido ser elogiada por los propios representantes del gobierno central. No cabe imaginar mayor responsabilidad y mayores deberes que los impuestos a las entidades locales con ocasión de la presente guerra; a ellas corresponde, por ejemplo, el principal papel en la defensa civil. $\mathrm{Y}$, sin embargo, responden admirablemente.

Cuando se dice que sobran entidades locales, conviene puntualizar en qué sentido se entiende esto. El actual sistema tripartito tiene ya 50 años de existencia, y, por lo tanto, es de suponer que las condiciones actuales no son las mismas que las de entonces. Ha aumentado considerableniente el número y la extensión de los servicios locales; y tan necesaria como la reducción del número de entidades es la creación de agrupaciones intermunicipales para realizar en común los servicios.

A pesar de las críticas que se hacen en el informe de la N. A. L. G. O. contra la presente estructura del gobierno local, este mismo comité no fuede por menos, de reconocer que ha desempeñado cumplidamente las tareas impuestas por la guerra, a causa del mejoramiento constante de la capacidad técnica de los funcionarios.

iSe ha llegado a creer, quizás con algún optimismo, que la administracićn local británica, ha conseguido el máximo de perfección constituyéndose en ejemplo del mundo entero. La actividad administrativa es impecable. Se administra lo mejor posible un organismo mal concebido y desproporcionado. Se ha conseguido la eficacia. Sin embargo, el crecimiento de la esfera local ha hecho pensar en la creación de nuevos organismos, de "entidades totales", con suficiente población, recursos económicos y atribuciones para administrar los servicios de una determinada región. Unánimemente se desea la creación de organismos regionales que se encarguen de los servicios comunes a varias entidades, a semejanza de las Delegaciones territoriales de los distintos Minisierios. Ahora bien, este regionalismo tendria que respetar la actual organización local, coordinando la actividad de sus diversas unidades, pero no venir impuesto desde fuera.

Además de las agrupaciones intermunicipales a que acabamos de referirnos se observa también la tendencia a establecer en los Distritos, unos organismos que administran directamente los servicios sin contar con la entidad local. La causa de este fenómeno está en que los servicios se considerarán cada día más, de importancia nacional y no de simple interés 
local. Hoy, la Educación y la Sanidad dan lugar a verdaderos servicios nacionales, pues si bien en un principio la intervención del gobierno en materia sanitaria, por ejemplo, se limitaba a señalar los deberes mínimos de las entidades locales, luego consistió, además, en un sistema de inspección y se llegó por fin a la creación de organismos provinciales directamente dependientes del Ministerio de Sanidad. Todo esto pone de manifiesto el aumento constante en todas direcciones del intervencionismo estatal, $y$, por consiguiente, de la burocracia.

Cualquiera que sea el esquema de organización futura que se adopte, hay que partir de la diferenciación entre los distintos tipos de entidades locales, porque siendo muy diferentes sus caracteristicas no puede aplicárseles unas mismas reformas. La uniformidad sólo sería posible si cada cuadrícula del territorio estuviera igualmente poblada y la industria homogéneamente distribuída, pero como esto, aunque fuera de desear, no se da en la realidad, hay que descartarlo.

Lewis Mumford en The culture of the Cities, afirma que no hay que pretender que todas las poblaciones sean iguales, sino que cada una esté en consonancia con la fertilidad de su comarca, las necesidades de su industria, etc. Dice también que a consecuencia del desarrollo de los medios de comunicación y transporte, la verdadera unidad de la vida social no es la ciudad, sino la región, pues los anteriores medios hacen inneoesaria la proximidad física para que pueda hablarse de convivencia.

Son sobradamente conocidas las distintas propuestas según las cuales se establece de modo matemático el volumen de las futuras "entidades totales". La Comisión de la N. A. L. G. O., señala la cifra de roo.000 habitantes. Mr. Geoffruy Boumphrey en Tozen and Country to morrow, habla también de cincuenta a cien mil almas. Thomas Shart en Town planuig y Ogburn en Social Characteristicas of cities partiendo de unos datos estadisticos demostrativos de la mayor baratura de los servicios en las grandes ciudades propugnan también la reunión de las pequeñas poblaciones en "entidades totales". Ebenezer Howard, padre de las ciudades-jardín, señala como ideal la ciudad cuyo núcleo central tenga 58.0oo habitantes, rodeado de seis satélites con 38.000 habitantes cada uno, separados por un amplio espacio verde; los siete grupos con una población total de 250.000 habitantes constituirán la entidad base de la administración local. Otros autores definen la necesidad de constituir agrupaciones aún mayores.

Sin embargo, esta opinión no nos parece acertada. Si bien, es verdad, que en economía indusirial es un axioma que las pequeñas empresas $636 \mathrm{no}$ pueden producir tan barato como las grandes, esto no rige en el cam- 
po administrativo puesto que el coste de la administración de las pequehas entidades es proporcionalmente mucho menor que el de las grandes. Conforme crece la población decrece la renta. No es cierto que en todo caso la mavor baratura de los servicios corresponda a un conjunto de 100.000 habitantes; esto sólo puede afirmarse de las ciudades, pero no de la población situada en una zona rural. $Y$ aunque parece a primera vista que la absorción de los distritos urbanos y de las pequeñas poblaciones por el condado habria de serles beneficiosa puesto que ahora deben contribuir a ous propios servicios y a los generales del condado, en realidad les interesa más conservar su autonomía porque nadie mejor que ellos puede conocer sus necesidades y los medios más convenientes para remediarlas. La cuantía de los impuestos no depende únicamente de la cifra de población, sino de un modo especial, de otros factores (geográficos, económicos, etcétera), como demuestra la estadística. Con la creación de ciudades satélites se ocasionaría una gran merma en la capacidad contributiva de los inmuebles de la ciudad originaria. Fsto conduciria al desequilibrio entre el valor de la propiedad en ambas ciudades. Las viviendas de la satélite serían más renombradas que las de la ciudad madre.

Una de las causas de las enormes cargas presupuestarias de las grandes ciudades radica en la necesidad que hubo, a consecuencia de los adelantos del transporte, de construir anchas calles y grandes vías en los lugares donde el terreno era más caro derribando las casas que allí se encontraban hacinadas. En cambio, este fenómeno no se ha dado en las ciudades pequeñas, que han permanecido estacionarias o cuyo crecimiento ha sido normal, sin experimentar la atrofia de las grandes. Las clases adineradas siguen residiendo en la ciudad $y$, por tanto, sus viviendas conservan una gran capacidad contributiva. Hay poca población obrera que siempre resulta una carga. Se desarrollan en ella muchas actividades y establecimientos que tienen la razón de su existencia en la atracción que ejerce sobre los pequeños poblados de su comarca. De aquí que el gravamen tributario por cabeza se reduzca al 50 ó 60 por roo del de las grandes ciudades, quedando, por tanto, un amplio margen para el establecimiento de nuevos servicios. $\mathrm{Y}$ con esto queda refutada la impugnación que ha querido hacerse de las pequeñas entidades locales afirmando que carecen de recursos suficientes. Habrá que buscar, si acaso, otros argumentos para sostener la conveniencia de la supresión de dichas entidades, porque, desde luego, el de la insuficiencia económica es totalmente infundado.

Por otra parte, el propio informe de la N. A. L. G. O., reconoce que la absorción de las entidades locales vendria a borrar sus peculiares caracteristicas, germen del espíritu cívico y del patriotismo local; y esta 637 
pérdida no podria compensarse con las ventajas administrativas que se pretenden obtener. Seria absurdo convertir a poblaciones como Oxford: o Cambridge en simples parroquias o quizá aún, en entidades con menos. atribuciones.

Hay que mantener la actual organización a base de los condados. Esun hecho que en los rurales existen menos impuestos que en las ciudades $y$, sin embargo, atienden un mayor número de servicios. La unión de varios condados en una nueva entidad administrativa se encontraría, además, con el inconveniente de abarcar zonas de desigual capacidad tributaria.

Teniendo en cuenta la distrjbución de la potilación en Inglateitra (sólo una sexta parte es rural) resulta que las cinco sextas partes de la opinión que ha de pronunciarse acerca del futuro del gobierno local, es urbana y más de la mitad pertenece a los burgo-condados y a Londres, con lo cual existe el peligro de que las pequeñas poblaciones sucumban, ante la coacción de una inmensa mayoría.

Es cierto que el éxito de la administración de los Consejos de Condado, se debe a que ha podido centralizar determinados servicios. También. es evidente que el Condado debe delegar algunas de sus funciones en Comités de Distrito que se encarguen de los servicios más propiamente locales. Pero estos comités deben ser los actuales Consejos de Distrito, de origen democrático; lo contrario significaría el establecimiento de un sistema oligárquico.

Si para una población de 100.000 habitantes que ocupe un reducida territorio puede resultar conveniente la creación de una sola entidad administrativa, no ocurre lo propio cuando el mismo número de habitantes. se encuentra diseminado en una gran extensión rural.

Queda, pues, plenamente justificado el mantenimiento de los Consejos de Distrito rurales y también de la mayoría de las entidades urbanas existentes. Su derecho a la vida no es más que un reflejo del indiscutible derecho que tienen y se reconoce a las pequeñas naciones a la independencia. Evidentemente los intereses locales se administran mejor desde cada localidad que a distancia, desde el centro.

La insuficiencia de recursos económicos no se remedia con la fusión de varias pequeñas entidades en una "entidad total" de 100.000 habitantes porque la capacidad tributaria por cabeza es la misma, considerando, en conjunto, una crecida suma de poblaciones que cada una de sus partes. por separado. La capacidad tributaria sólo aumentará con la agregación si a una zona pobre se le une otra más rica pero entonces incurre em la. 638 injusticia de hacer que unos vivan a expensas de otros. 
Las pequeñas comunidades deben administrarse como lo que son, y resultaria mury artificioso pretender someterlas a unos moldes preconcebidos. Además, las entidades locales son muy œlosas de su autonomía, como ha podido verse, por ejemplo, con la resistencia opuesta por los Consejos de Condado a la ampliación de los límites de los burgo-condados. Aunque el crecimiento de la ciudad no ha sido contenido por los condados limitrofes que no se han opuesto a ello, en cambio, si, se han resistido a que ampliara sus límites. Sin embargo, los Consejos de Distrito rurales se han visto imposibilitados de dotar de servicios al exceso de población de la ciudad vecina y en algunos casos ésta ha tenido que incorporar bajo su jurisdicción la zona de ensanche, ampliando alli sus servicios, lo cual ha resultado más económico que el crearles de nuevo. El ensamche de las poblaciones hace preciso el establecimiento de intimas conexiones con la condados limítrofes, dentro de la actual organización administrativa, a base de una especie de federalismo presidido por un espiritu de tolerancia y sentido de mutua independencia.

La superpoblación de las grandes ciudades plantea grandes problemas, especialmente el de asegurar a la población el disfrute del derecho inviolable a las condiciones mínimas de vida. Ante este derecho vital deben ceder todos los respetos que merecen los límilies de los condadas y ha de llevarse a cabo el establecimiento de un organismo regional o la federación de las entidades locales afectadas.

Mr. Orborn defiende el proyecto de evacuar do Londres buena parte de su población (dos millones en el condado y otros dos millones fuera de él), creando, al efecto diez o veinte ciudades satélites. Veamos si es factible la idea. Mr. Osborn cree que construyendo 60.000 casas al año, dentro de veinte años habría terminado la evacuación. Esto representa un gasto de doscientos millones de libras más otros cuarenta millones que costaría la prolongación del metro, sin contar con la ampliación del alcantarillado y otros servicios y los que se pretenden invertir en el embellecimiento de Londres (derribo de casco antiguo, etc.).

Según el informe del Departamento de Sanidad del municipio de Mánchester, 70.000 casas de la ciudad no reúnen las condiciones higiénicos debidas. $Y$ se propone el derribo de 10.000 casas por año simultáneamente con la construcción de otras tantas nuevas. Hay que advertir, que hasta el presente, el año que más construcciones se hicieron, no pasaron éstas de 5.000. Además, un somero examen del aspecto económico del problema demuestra que el capital invertido en las nuevas construcciones no produciria ninguna renta. Por lo tanto, como no hay que 
esperar que la gente se sienta filantrópica, sino que de ordinario se mueve por el interés económico, no habrá quien las edifique.

Lo que necesita Inglaterra ante todo, es asegurar la importación de las subsistencias y primeras materias, teniendo los suficientes recursos para poderlas pagar, y estos recursos debe obtenerlos de la exportación. $\mathrm{Si}$ por los cuantiosos dispendios ocasionados por fantásticos proyectos se gravan de modo excesivo las fuentes de producción, no habrá mercados para los productos ingleses y con el colapso de la exportación se carecerá también de medios para adquirir los productos básicos que necesita del extranjero.

Tampoco está plenamente justificada la demolición sistemática de las casas del casco antiguo de las poblaciones, como viene haciéndose de un tiempo a esta parte, pues muchas de ellas reúnen condiciones higiénicas de habitabilidad. Es un caso nunca visto de expropiación, sólo comparable al de las antiguas revoluciones agrarias. Es absurda la propuesto del Uthwat Comitee pidiendo la expropiación, en un plazo de diez años, de todas las antiguas construcciones que, aunque no sean inhabitables, no están en armonia con el estilo, alineación y distancias exigidas a las modernas. Como afirmó Holford, hay en Inglaterra cuatro millones de casas que tienen más de ochenta años, y un millón de paso, que tienen más de I $_{50}$. es decir, que un tercio de los edificios ingleses deberian demolerse, con lo cual muchas ciudades perderian sus mejores encantos.

Un buen argumento contra los planes de reforma administrativa que pretenden distribuír la población según un criterio matemático, puede sacarse de los datos estadísticos contenidos en los propios planes reformistas (plan Barlow, etc.), que demuestran el excelente funcionamiento de los servicios sanitarios locales. La mortalidad acusa una notable disminución; ha pasado del 21,4 por 100 en el período de 187 I-80, al I2 por Ioo entre I93I-35. El promedio de educación de la vida humana ha subido de los 25,18 años en I864, a 60,2 los hombres y 64,4 las mujeres en I943. $Y$ lo curioso res, que el nivel sanitario as más ielevado en la ciudad que en el campo. Como afirma el doctor Philips en su informe al Town Planning Institute de junio de 1942 , la sanidad no tiene nada que ver con la dimensión de las ciudades, sino que depende de la latitud, de las clases sociales, de las condiciones de las viviendas, etc. Londres es el punto que goza de mayores ventajas higiénicas, siendo como es una gran ciudad. Por otra parte en las pequeñas ciudades es donde los servicios sanitarios están mejor organizados. De aquí que, contrariamente a lo que se pretende en el plan de Barlow no hay por qué desmembrar las grandes ciudades ni agru640 par las pequeñas, puesto que en unas y otras se dan excelentes condicio 
nes higiénicas. El alto nivel sanitario alcanzado hoy día lo ha sido gracias al desenvolvimiento natural de la población y a los adelantos de la medicina. Toda alteración artificiosa de este proceso normal acarrearía, en cambio, graves trastornos.

La menor mortalidad en las ciudades respedtio del campo no sólo so da en Inglaterra sino en otros países, por ejemplo, Holanda. Y la cifra de mortalidad disminuirá aún más si se aleja de las ciudades el humo de las fábricas, y se mejora la urbanización, los medios de transporte y la alimentación. En materia sanitaria tiene, en cambio, poco importancia la fijación de una densidad máxima de 12 casas por acre propugnada en los planes de reforma.

Otro argumento contra la dispersión de las poblaciones urbanas es su carácter antieconómico, pues ocasionaría considerables pérdidas de tiempo y de dinero, contribuyendo al descenso del índice alimenticio familiar. A la Sanidad le interesa solamente que las viviendas estén bien aireadas y soleadas, que el índice de alimentación sea elevado, que se supriman innecesarios gastos motivados por largos desplazamientos y que se purifique la atmósfera alejando de las poblaciones las industrias productoras de humos. Por lo tanto, el primer principio de urbanismo debe ser que las viviendas se construyan lo más próximas posible a los lugares de trabajo.

Mr. Pink en Social Reconstrución señalal Itambién la insuficiencia de alimentación de las clases humildes.

Las grandes ciudades tienen planteado otro grave problema: el relativo a la población escolar. Se ha criticado mucho el sistema de enseñanza británico, que se imputa a la especial estructura económica del país. Pero no puede remediarse el mal en un solo día. Cualquier programa de reforma debe realizarse por etapas. Cierto que muchos lugares resultan insanos para la vida del niño y que hay que buscar otros más saludables. Pero esto no está en las manos de la Administración local. Aunque la N. A. L. G. O. diga que el primer deber de las autoridades locales consista en asegurar el bienestar de los administrados, esto no pasa de ser una utopía si no se entiende bajo ciertas limitaciones. El bienestar social no depende sólo de la actividad administrativa sino más principalmente del sistema industrial. Las condiciones sociales han mejorado y siguen mejorando mucho, pero no podemos creer que esta progresión será definida. La capacidad rentable del país tiene un límite del que se deriva, como lógica consecuencia, el tope de las exacciones fiscales que son la base económica de los servicios administrativos.

Digamos algo acerca de los gastos municipales. Es fundamental en 
esta materia la obra del profesor Hicks titulada Standards of Local Expenditure $-A$ problem of the Inequality of Incomes.

Interesa señalar el gravamen que los gastos públicos suponen por habitante más bien que relacionarlos con la unidad monetaria. Desde luego este gravamen es muoho menor en las pequeñas poblaciones que en las grandes, lo cual confirma una vez más la tesis de la mayor baratura de la administración de las pequeñas entidades locales. En los grandes municipios el reparto de los gastos entre la población supone un gravamen medio de seis libras, diez chelines; mientras que en los pequeños es sólo de dos libras, quince chelines.

A través de interesantes datos estadísticos puede verse el progresivo aumento de los gastos municipales, llegando a gravar anualmente por término medio a una familia de 3,5 personas con una exacción de cerca de veinte libras, a las que hay que añadir el importe de las contribuciones estatales sobre la edificación y otras.

La máxima inflación se dió én el año 1922 en el que se realizaron los mayores gastos siendo más bajo el valor de la moneda.

En relación con el límite de la capacidad impositiva hay que señalar la diferencia entre los impuestos sobre la propiedad y los impuestos sobre la

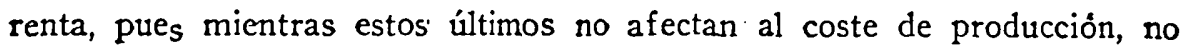
ocurre lo mismo con los primeros. Por esto, las exacciones locales, que se imponen sobre la industria por el mero hecho de ejercerla aunque no haya ganancias, vienen a convertirse para el empresario en gastos de establecimiento, que contribuyen a elevar el coste de los productos, y repercuten desfavorablemente en la capacidad de la industria nacional, para competir con la extranjera. En las épocas de depresión, el daño es mayor porque fabricándose menos y siendo igual el impuesto, aumenta el gravamen sobre cada producto.

Afirma el profesor Hicks que, de no haber sido por la guerra, en r940 la situación de las haciendas locales hubiera representado un grave problema político; y es de suponer que tan pronto termine, pasará a ocupar el primer plano de la actualidad. Uno de sus principales aspectos es el relativo a la desigualdad tributaria entre las distintas localidades. Se da el caso de distritos que pagan un 50 por 100 más que otros del mismo condado debido a que ocasionan mayores gastos o a que tienen menor líquido imponible y hay que elevar los tantos por ciento para cubrir unos mismos gastos. Un gravamen elevado significa que la Administración quiere estableoer un nivel antormal de servicios o que la zona es pobre y sólo con este exceso de imposición pueden atenderse los servicios normales. $\mathrm{Y}$ como las 642 zonas industriales suelen ser pobres han de soportar mayores tributos, 
con la consiguiente elevación del coste de los productos y éxodo de la industria hacia zonas menos gravadas. De aqui que se sintiera la necesidad de rebajar los impuestos.

Es preciso, pues, llamar la atención sobre el peligro que suponen los cuantiosos gastos de la Administración local y desvanecer los sueños dora-dos que han querido suplantar la realidad. Aunque se puede ser realista sin ser cínico, se nos tachará de esto último si recordamos los informes optimistas que se dieron hace tan sólo diez o doce años acerca de la Administración local, recomendando la reducción de los gastos municipales.

Míster Robson, en That Municipal Debt, afirma que así como el capital de una compañía mercantil viene a representar una deuda contraida con los accionistas, así también la deuda municipal es el capital de que dispone el Municipio. La deuda municipal se ha acrecentado constantemente con nuevos empréstitos. En 1884 ascendía a I7I millones de libras, y en I930 era ya de I.I 57 millones. Esto supone un gasto de 85 millones en pago de inrereses.

Otro problema a estudiar en materia de haciendas locales es el de si el Municipio es la entidad que resulta más económica para la exacción de impuestos o si sería mejor repartir las cargas tributarias sobre una base de población más amplia para que el reparto fuera más equitativo. Podrian aún *itarse otras muchas cuestiones.

Pero lo que más nos interesa examinar a propósito de lo que deba ser La Administración local en el futuro es cuál sea la tendencia del movimiento demográfico, es decir, si la población va a estacionarse, aumentar o disminuir.

Ya se ha consignado la mayor duración de la vida humana de hoy respecto del siglo pasado. Esta creciente longevidad, junto con la estabilización de la cifra de nacimientos, podria hacernos creer en un progresivo aumento de la población. Sin embargo, esta predicción, que pudo ser cierta en los primeros tres cuartos del siglo XIX, no puede admitirse hoy día. Hoy hay que pensar en la disminución de la población. La misma longevidad dará lugar al aumento del número de ancianos. Míster Morrison, en un estudio estadistico de 7 de mayo de I943, acusa el peligro del descenso de la población al señalar que actualmente hay en Inglaterra la misma población infantil que en I876, cuando la población total era casi la mitad de la de hoy. Hace cuarenta años, en tiempo de la guerra de los bóers, había I.500.000 niños más que ahora. Si este movimiento demográfico no se rectifica, a últimos de siglo la mitad de la población tendrá más de sesenta años, lo cual significaría ta extinción próxima del pueblo inglés. El descenso en la cifra de nacimien- os progresa rápidamente. Míster Grebenik, refiriéndose a la ciudad de Bris- 
tol, asegura que alcanzará su máximo de población en 1947 con 416.000 habitantes, y que a partir de esta fecha se iniciará el descenso, llegando a. tener sólo 273.000 dentro de sesenta años. La población infantil disminuirá aún más de prisa: de 6r.200 niños en 1937 pasará a 43.300 en 1967 y a 29.100 en el año 2002 .

Hace cuarenta años se abolieron los antiguos departamentos de enseñanza y la educación corrió a cargo de los condados y de las grandes entidades locales. La población de las ciudades ha aumentado, mientras el campo se ha despoblado. Hemos rendido culto a las grandes Corporaciones. Sin embargo, no puede decirse que hoy las escuelas elementales estén mejor dotadas que hace cuarenta años.

Volviendo a la población, es curioso citar una estadística de míster Wilson publicada en 1935 por el Institute of Public Administration, según la cual el número de niños varones comprendidos entre los cinco y los nueveaños de edad pasará de 1.605 .000 en 1932 a 989.895 en 1962 (61,6 por I00), mientras que el número de ançianos comprendidos entre los ochenta y los. ochenta y cuatro años subirá de 86.200 a I 179.463 (más del Ioo por Io0) en el mismo período de tiempo.

Sin embargo, el doctor Percy Stocks, en el British Medical Journal de 21 de marzo de 1942, sostiene la opinión contraria, creyendo que es un error esperar un rápido descenso de la población, pues, según los datos. obtenidos por la General Register Office a base de 700.000 nacimientos anuales y un promedio de vida de $60-76$ años, la población permanecerá estacionaria, si bien con un mayor número de ancianos si sigue decreciendo la mortalidad.

Creemos que el cálculo del Register General es demasiado optimista, porque mantiene constante la cifra de nacimientes, a pesar de que disminuye el número de mujeres comprendidas entre los quince y los cuarenta y cinco años. Así lo advierte el doctor Kuczyuski en The New Population Satistics, lamentando que no se conceda al grave problema demográfico inglés toda la atención que merece, dados los peligros que encierra.

La disminución de la cifra de nacimientos-afirma Mr. Harrod en Britrin's Future Population-no se debe a un empeoramiento de las condiciones de vida, puesto que, por el contrario, se ha producido precisamente cuando el nivel de vida se ha situado muy por encima de lo que hubieran podido soñar nuestros antepasados, que, en medio de calamidades, enfermedades y hambres, no se cansaron de dar hijos al mundo.

Pensemos en la repercusión de la innegable realidad del descenso de población respecto de los planes de reforma del régimen local que propugnan 644 la dispersión de los núcleos urbanos en ciudades-satélites y respecto de la 
industria, del comercio, de los servicios sociales, etc. Cuando esta disminución sea un hecho, la cifra de roo.000 habitantes señalada como mínima para la constitución de una entidad local obligaria a situar bajo una misma autoridad enormes extensiones territoriales. Es de suponer que la mayoría de las zonas superpobladas dejarán luego de estarlo. Míster Bossom cree. que quedarán cinco millas de terreno agrícola alrededor de cada ciudad de50.000 habitantes y que llegaremos a ver poblaciones desiertas.

Lo primero que hay que hacer, pues, cuando se habla de reorganizar el futuro gobierno local es tener en cuenta las condiciones que se darán en el futuro. $\mathrm{Y}$ si se observa una tendencia hacia el descenso de la población es absurdo planear la reforma como si la densidad de población tuviera que aumentar.

Lo que tiene que preocupar a los reformadores es el aseguramiento de las subsistencias y de las materias primas y la disminución de las importaciones para lograr la independencia económica respecto del extranjero. Hay que controlar las importaciones y aumentar el consumo de los productos nacionales. Esto exige un mayor desarrollo de la agricultura y sus industrias derivadas que influirá profundamente en el régimen local, pues aumentará la población y el bienestar de las zonas rurales. Más que preocuparse por las ciudades hay que atender al campo y a su futura organización.

(Traducción y extracto de L. Lopez Rodo). 